\title{
SYPHILITIC OPTIC NEURITIS
}

\author{
BY
}

\author{
G. S. GRAVESON
}

\section{From the Department of Neurology, Manchester Royal Infirmary}

The broad division of syphilitic disease of the central nervous system into parenchymatous and meningo-vascular types has proved of considerable value, both in understanding the pathological processes involved in the clinical patterns of disease and in estimating their prognosis. Its application to syphilitic disease of the optic nerve has been neglected ; for whereas parenchymatous degeneration manifesting itself as a so-called primary optic atrophy is well known, yet its counterpart-an inflammatory neuritis of the optic nerve-is ill defined in the literature and indeed seldom mentioned. Partly, no doubt, this is because it is a rarer disease and partly, perhaps, because its effects are less serious and, therefore, have not created as much interest. Nevertheless, it is a condition of some importance, and its clinical features merit more attention than has hitherto been given to them. In this paper an attempt is made to define the clinical picture of syphilitic optic neuritis more sharply on the basis of a study of five cases seen in the last two years.

\section{Case Reports}

Case No.1.-A. R., a policeman, aged 37, was admitted to hospital in January, 1948 , complaining of defective vision. He had first noticed a loss of acuity in the right eye in October, 1947. Whilst playing snooker one day he discovered that he was unable to see clearly the ball he was aiming to hit. Gradually, from this time onward, his distance vision became impaired and within a month near vision was also involved, so that he had difficulty in reading his writing with this eye. Between November, 1947, and January, 1948, no further deterioration occurred. Vision in the left eye was affected about three weeks after the onset in the right eye. There was a very slight deterioration in distance vision which had not progressed after the first month. He had had no ocular pain or headache.
On examination his visual acuity was 6/24: 6/6. Both fundi showed identical changes. The optic disc was hyperæmic and its margin was obliterated, the pink colour of the disc blending with that of the retina. The retinal veins were engorged but not obscured by the disc changes. There was no measurable swelling of the optic nerve head. The appearances were those of a papillitis. The fields of vision showed a central scotoma to a $3 \mathrm{~mm}$. white object in both eyes, a complete ring scotoma to a $10 \mathrm{~mm}$. white object in the right eye, and a partial ring scotoma in the left eye. Coloured targets were not seen at all and further testing revealed that he had become, in fact, completely colour-blind. Both eye-balls were tender on pressure over their superior poles.

Neurological examination was otherwise normal and there were no cardiovascular changes. The blood Wassermann reaction was positive 1 in 8 . The cerebrospinal fluid was normal in composition ( 1 cell per c.mm. ; $35 \mathrm{mg}$. protein per $100 \mathrm{ml}$.; globulin, no increase; Lange curve 0000000000$)$; the Wassermann reaction was negative.

A diagnosis of syphilitic retrobulbar neuritis was made and the patient was discharged from hospital and

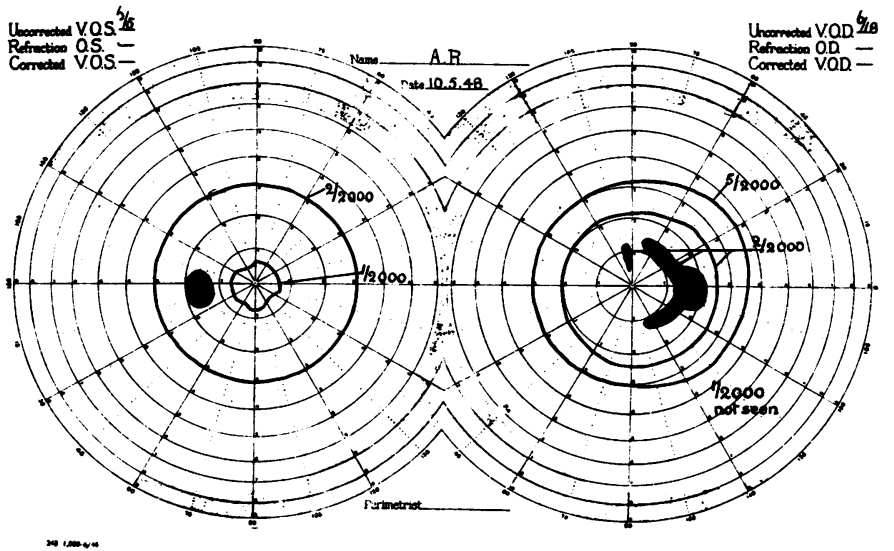

Fig. 1.-Case 1. (May, 1948) V.A. 6/18, 6/6. White targets. R. eye : enlarged blind spot, two nerve bundle scotomata and a small paracentral scotoma to $2 / 2000$. $1 \mathrm{~mm}$. target not seen. L. eye : enlarged blind spot; constriction of $1 / 2000$ isopter. 
out-patient treatment at his local clinic arranged. After two weeks preliminary treatment with bismuth (total $6 \mathrm{ml}$. "stabismol") he was given 4 mega units of penicillin, followed by a two months' course of intravenous arsenic $(5.05$ g.) and intramuscular bismuth (15 ml. "stabismol ").

now seen for $2^{\circ}$ around the fixation point. The left field was unchanged.

One further course of arsenic ( $30 \mathrm{ml}$. " acetylarsan ") and one of bismuth (20 ml. "stabismol ") were given and the patient was seen again in May, 1949. He was then very well, his only symptom being the distortion of vision in the right eye. Visual acuity was $6 / 6: 6 / 6$. The discs were normal in colour, but the edges were blurred and the physiological cup was filled. The patch of choroiditis in the right fundus was densely pigmented and appeared to be healed. The fields of vision (Fig. 2) showed an expansion of the $1 / 2000$ isopter to about $10^{\circ}$ in each eye. The scotomata on the right side were unchanged. The red fields had expanded though they were still considerably constricted. The blood Wassermann reaction was now negative.

It was impossible to be sure of the date of this patient's primary infection. He had been married ten years and his wife was found to have a positive blood Wassermann reaction. He denied extramarital exposure to infection after his marriage. It seems most likely that he acquired his disease before then and transmitted it later to his wife. His

In May, 1948, his visual acuity had improved to 6/18 : $6 / 5$ and the bilateral papillitis had subsided. There was a slight pallor of the discs and their edges were a little indistinct. In the right fundus there was a small patch of choroiditis just below the macula which was responsible for a distortion of vision noticed just above the fixation point ; a vertical straight line appeared wavy at this point. The fields of vision had also improved (Fig. 1). The blind spot was enlarged in each eye. The right field showed a partial ring scotoma due to two nerve bundle defects, and also a paracentral scotoma corresponding to the patch of choroiditis. The 2/2000 isopter was constricted and the $1 \mathrm{~mm}$. target not seen at all. Colour vision had returned in the central part of the lower nasal quadrant, a $20 \mathrm{~mm}$. red target being visible here. The left field showed only a constriction of the 1/2000 and 2/2000 isopters. The blood Wassermann reaction was positive 1 in 4 . A further course of bismuth and arsenic was given (30 ml. "acetylarsan" + $10 \mathrm{ml}$. "stabismol").

In September, 1948, visual acuity was $6 / 9: 6 / 6$. The disc margins were still indistinct, due to connective tissue overgrowth, but no œdema was present. The patch of choroiditis in the right macular area had become more pigmented. The right field of vision had improved. The partial ring scotoma was smaller and the $1 \mathrm{~mm}$. target was

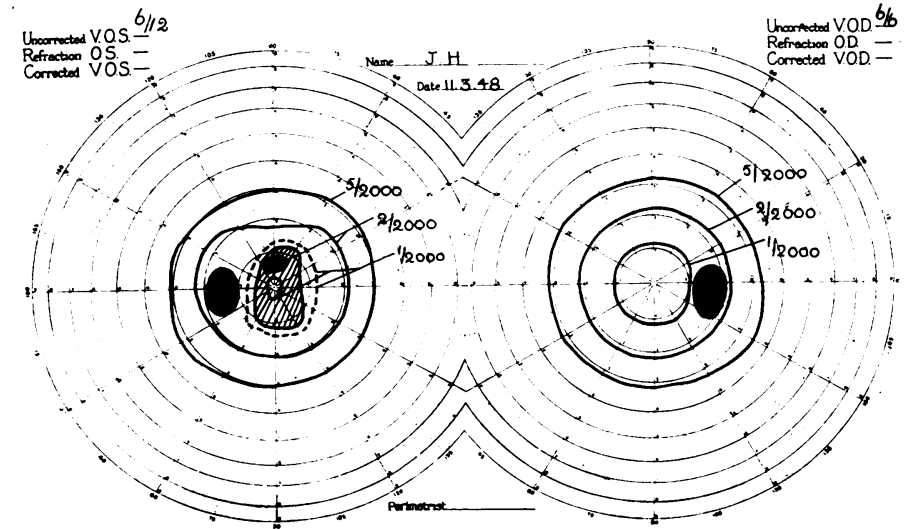

FIG. 3.-Case 2. (March, 1948) V.A. 6/6, 6/12. White targets. R. eye : enlarged blind spot. L. eye : enlarged blind spot; broad ring scotoma to $1 / 2000$, paracentral scotoma to $2 / 2000$, slight concentric constriction of $1-5 / 2000$ isopters.

then improved a little.

On examination his corrected acuity was $6 / 6: 6 / 12$. Fundal examination revealed a bilateral papillitis. The

Case No. 2.-James H., aged 33 years, was first seen A month previously he had awakened one day to find that vision in his left eye was blurred. There was no accompanying headache or ocular pain.
The blurring remained unchanged for two weeks and 
discs were hyperæmic and the edges blurred though their position could be identified. The retinal veins were slightly engorged but there were no hæmorrhages or exudate. The right field of vision (Fig. 3) showed an enlarged blind spot and a slight contraction of the 1/2000 white isopter. The left field revealed a broad ring scotoma to $1 / 2000$ and a small paracentral scotoma to $2 / 2000$. The blind spot on this side was also enlarged. The $5 / 2000$ and $10 / 2000$ red isopters were considerably contracted, whilst a $5 \mathrm{~mm}$. green target was not seen with either eye. The $10 \mathrm{~mm}$. green target was not seen on the left and only within $5^{\circ}$ on the right. Physical examination was otherwise normal.

The Wassermann reaction was positive in the blood $(1$ in 8$)$ and cerebrospinal fluid, and the latter cortained 47 lymphocytes per c.mm.; $55 \mathrm{mg}$. protein per $100 \mathrm{ml}$.; a slight excess of globulin (Pandy) and a Lange curve 01121100000 .

He was given 4.2 mega units of penicillin $(200,000$ units daily for three weeks). Six weeks later his acuity was $6 / 6$ right and left, though there was still a subjective haziness of vision in the left eye. Perimetry now showed only a small paracentral scotoma in the left field and a constriction of the $1 / 2000$ isopter.

Re-examination of the fields of vision in May, 1948, showed that the scotoma in the left field of vision had disappeared. The blind spots were smaller and the $1 / 2000$ isopters had expanded, though they were still constricted a little. The disc appearances, however, were unchanged. He was then given a course of eight weekly injections of $0.3 \mathrm{~g}$. " kharsulphan " together with potassium iodide gr. 10 t.d.s. and pil hydrarg c. creta gr. 1 t.d.s. by mouth, and this was followed by ten weekly injections of $0.07 \mathrm{~g}$. " bivatol ".

In August, 1948, the visual acuity was still 6/6: 6/6; the discs showed blurred margins without swelling, due to overgrowth of connective tissue. The fields of vision were almost normal. The blood Wassermann reaction was positive 1 in 4 ; the cerebrospinal fluid was normal in composition and the cerebrospinal fluid Wassermann reaction negative. After a rest period he was given a second course of penicillin, in January, 1949 (600,000 units daily for six days) and a third and similar course in April, 1949.

In May, 1949, the disc appearances and the fields of vision were unchanged, except for a slight expansion of the $1 / 2000$ isopter in the left eye (Fig. 4); the blood Wassermann reaction was still positive 1 in 2 .

Case No. 3.-Ellen H., aged 44, the wife of James H. (Case 2), was first seen in February, 1948 , complaining of blurring of vision in the right eye of six weeks' duration. The mistiness of vision, initially of sudden onset, increased for two weeks and then remained

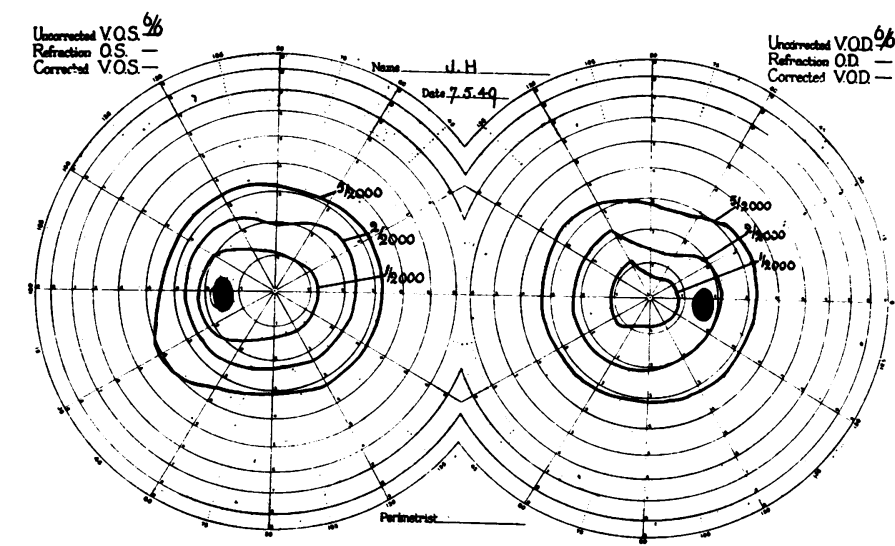

Fig. 4.-Case 2. (May, 1949) V.A. 6/6, 6/6. Fields for white targets now show reduction in size of blind spots, with a disappearance of the scotomata and expansion of isopters in L. eye. In R. eye 1-2/2000 isopters are a little smaller than in Fig. 3.

stationary. For the first three weeks she suffered $\frac{0}{\circ} \underset{\sim}{\omega}$ from headaches over the right eye and in the right $\vec{D} \vec{\sigma}$ temporal region. Four months previously she had $\stackrel{?}{\mathbb{D}}$ 을 developed a red macular rash over the arms, neck and $\varrho$ trunk. It had lasted six weeks and left a brownish discoloration over the skin. At the same time she noticed that her hair was beginning to fall out.

Examination showed widespread patchy areas of brownish pigmentation of the skin of the neck, trunk and arms and a diffuse alopecia of the scalp. The discs showed a bilateral papillitis. In the right eye the swelling of the disc head extended for a distance of 2-3 disc diameters into the surrounding retina,

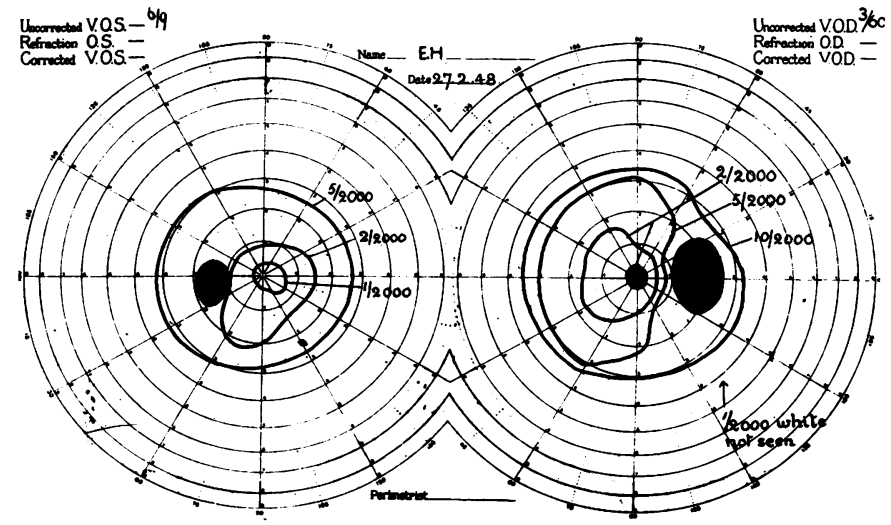

Fig. 5.-Case 3. (February, 1948) V.A. 3/60, 6/9. White targets. R. eye : greatly enlarged blind spot ; dense pericentral scotoma to $2 / 2000$. Constriction of $2-5 / 2000$ isopters. $1 \mathrm{~mm}$. target not seen. L. eye : enlarged blind spot with constriction of $1-2 / 2000$ isopters. 
obscuring the disc margin and the vessels crossing it. The retinal veins were distended, but there were no hæmorrhages or exudate. In the left eye there were similar but less pronounced changes. Visual acuity was $3 / 60: 6 / 9$. The right field of vision (Fig. 5) showed a small, dense, pericentral scotoma and an enlargement of the blind spot. The peripheral field was full $(3 / 330)$, but there was a constriction of the 5/2000 and $2 / 2000$ white isopters, whilst the $1 \mathrm{~mm}$. white target could not be seen. In the left eye the blind spot was enlarged, but there was no central scotoma. The 1,2 , and $5 \mathrm{~mm}$. white isopters were constricted and also the $2-10 \mathrm{~mm}$. red isopters. Neurological examination was otherwise normal.

The blood Wassermann reaction was positive 1 in 8 . The cerebrospinal fluid was normal in composition (1 cell per c.mm. ; $25 \mathrm{mg}$. protein per $100 \mathrm{ml}$.; globulin, no increase; Lange curve, 0000000000 ), and the Wassermann reaction negative.

The patient was given, first, four weekly injections of bismuth $(1 \mathrm{ml}$.

"bismostab") and then 4.2 mega units of penicillin $(100,000$ units b.d. for three weeks). This was followed by alternating courses of arsenic $(0 \cdot 3 \mathrm{~g}$. "sulpharasine" for eight weeks) and bismuth oxychloride $(0.75 \mathrm{ml}$. " chlorostol" for eight weeks), three of each in the next twelve months.

Two months after the beginning of treatment in April, 1948, there had been a considerable improvement in her condition. Her hair had begun to grow again and the rash had almost completely disappeared. Her visual acuity was now $6 / 18: 6 / 6$. The right disc was still hyperæmic and its margin was blurred, but the left disc was normal. The fields of vision showed enlargement of the blind spots and constriction of the smaller isopters. The $1 \mathrm{~mm}$. target was still invisible on the right side. In June, 1948, her acuity was 6/9:6/5. The $1 \mathrm{~mm}$. target was seen up to $10^{\circ}$ in the right eye, except for a minute area at the fixation point $\left(<1^{\circ}\right)$. By August this small scotoma had disappeared, the blind spots were smaller in size, and the 1-2/2000 white and 3-10/2000 red isopters had expanded considerably.

She was not seen again until July, 1949, by which time her hair had regrown completely and there was no trace of the old skin eruption. Her visual acuity $(6 / 9: 6 / 6)$ and the fields of vision (Fig. 6) had not changed in the preceding twelve months. The discs were quite normal in appearance, except that no physiological cup was visible in either eye. The blood Wassermann reaction was now normal.

The occurrence of this rare condition at the same time in man and wife must be unique. Unfortunately, it was not possible to be certain how each acquired infection. The husband gave a history of urethral discharge at the age of 18 and again at 31 , that is 18 months before the onset of the optic neuritis. Because of this relapse marital intercourse ceased. Yet his wife had a secondary stage rash with alopecia at the time her optic neuritis occurred. Both denied extramarital intercourse at any time. It is felt, however, that each of

Fig. 6.-Case 3. (July, 1949) V.A. 6/9, 6/6. Fields now show almost normal blind spots and expansion of 1-2/2000 isopters. No pericentral scotoma in the R. eye.

them acquired infection in this way at different times and that the simultaneous development of optic neuritis was a coincidence. In the husband's case the neuritis was, therefore, a feature of the tertiary stage.

Case No. 4.-J. C., a man of 61 , was first seen in October, 1949. Five weeks previously he had awakened to find that vision in his right eye was misty. This slowly got worse for a week, by which time he could not see to read with the eye and distance vision was reduced to about six yards. After a fortnight there was some improvement, and when first seen he could read newspaper headlines. At no time did he have ocular pain or headache.

Examination revealed an acuity of $6 / 18: 6 / 9$. Both optic discs showed the changes of papillitis : hyperæmia, blurring of the margins, disappearance of the physiological cup. The retina was normal. Ocular tenderness was not increased. The only other neurological abnormalities were an absence of the ankle jerks, a diminution of vibration sense at the ankles, and a persistent jerking nystagmus to right and left. The blood Wassermann reaction was found to be positive 1 in 8.

He was admitted to hospital on October 25. The ocular signs were unchanged except for a further reduction in vision to $6 / 36: 6 / 12$. The fields of vision (Fig. 7) showed a concentric construction of white isopters with disappearance of the smaller ones-more marked in the right eye than the left. The blind spots were enlarged in both eyes. There were no scotomata. Colour fields were correspondingly affected. Examination of the cerebrospinal fluid showed 110 lymphocytes per c.mm., proteins $50 \mathrm{mg}$. per $100 \mathrm{ml}$., globulin increased, Lange curve 5543321000, and the Wassermann reaction positive. 
The patient was treated with 600,000 units procaine penicillin daily for three weeks. Improvement by the end of this period was striking. Visual acuity was now $6 / 18: 6 / 9$. The visual fields had expanded considerably

who was found to have syphilis in 1946, since when no intercourse had taken place. It would appear, therefore, that his optic neuritis was a tertiary manifestation and his other neurological abnormalities

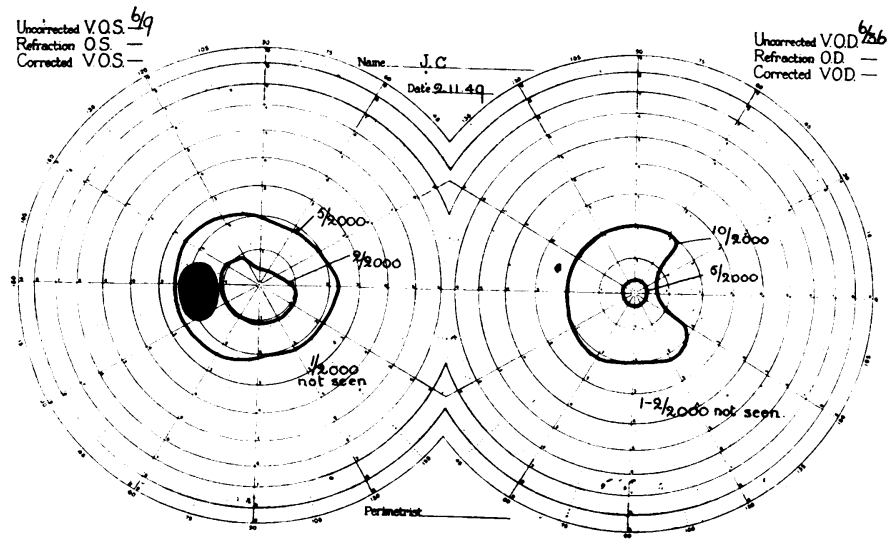
tend to support this conclusion.

Case No. 5.-H. S., a man aged 37 years, was admitted to hospital on August 29, 1949. He gave the following history. Sixteen years ago he had developed a right-sided ptosis, apparently without diplopia, which cleared up spontaneously in two to three weeks. A year later he awoke one morning to find he was almost completely blind in the right eye. There was no accompanying pain or headache. No change in the vision of this eye had ever occurred and he was only able to see movements with it. For at least ten years he had known that he had lost his sense of smell. For eight years he had been aware of muscle spasms affecting the left side of his face. Three weeks before admission he noticed one morning a blurring of vision in the left eye. This rapidly increased and within a week he was unable to

and the papillitis was subsiding. The cerebrospinal fluid had improved also ; 29 lymphocytes per c.mm., proteins $50 \mathrm{mg}$. per $100 \mathrm{ml}$., Lange curve 334332100 .

By January, 1950, his acuity was normal 6/6: 6/6. The fields of vision (Fig. 8) showed further improvement and the papillitis had almost completely subsided without atrophy developing. The blood Wassermann reaction was still strongly positive. Treatment is being continued with arsenic and bismuth injections.

It was impossible to discover the date of primary infection in this patient. He denied symptoms of the primary and secondary stage at any time. It seems probable that he acquired the disease from his wife,

see anything clearly.

Examination revealed bilateral anosmia; bilateral facial paresis $(L>R)$ with inability to whistle ; intermittent shock-like spasms affecting, simultaneously, the whole of the facial musculature on the left side. Pupils were both regular, $\mathrm{R}, 3 \mathrm{~mm}$.; $\mathrm{L}, 4 \mathrm{~mm}$.: the left contracted briskly to light; the response of the right was poor and ill-sustained. Vision was reduced to: right, hand movements; left, 2/60. The right optic disc showed the appearances of secondary atrophy. It was dead white in colour, its margins were not clear cut, and the physiological cup was filled. The retina and vessels were normal. The left fundus showed an enormous swelling of the disc head with a prolongation of the œedema along the superior temporal vessels. The veins were distended, especially the superior temporal, and there were hæmorrhages around this vessel which appeared to be the seat of a periphlebitis. In the macular area was a cluster of refractile hard exudates. The vitreous was hazy and, in addition, there was an old vascularized keratitis near the inferior limbus. The fields of vision (Fig. 9) showed a persisting island of peripheral vision on the right side. Originally he must have had a large central scotoma which broke out into the periphery of the visual field. In the left field the 5 and $10 \mathrm{~mm}$. white targets were seen vaguely but it was possible to detect an enlargement of the blind spot. There was no central scotoma. 
The Wassermann reaction was strongly positive in the blood but negative in the cerebrospinal fluid. The latter was under normal pressure $(130 \mathrm{~mm}$.) and was normal in composition ( 4 cells per c. mm., proteins

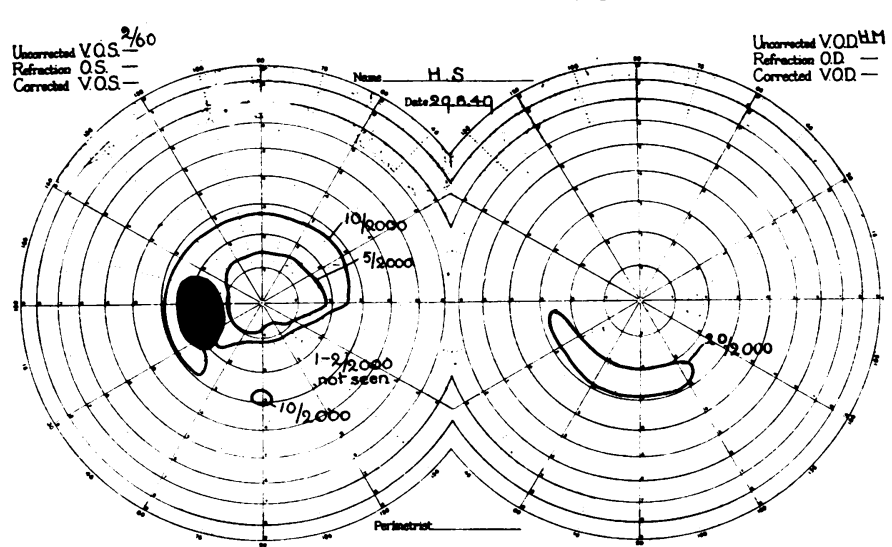

Fig. 9.-Case 5. (August, 1949) V.A. H.M. 2/60. White targets. R. eye : peripheral island of vision in lower nasal quadrant to $20 \mathrm{~mm}$. target. L. eye : greatly enlarged blind spot with constriction of isopters especially in the lower quadrants. 1 and 2 $\mathrm{mm}$. targets not seen. Vision very hazy in the preserved field.

(Fig. 10) showed much improvement. It was now possible to define a nerve bundle scotoma in the inferior half field on the left. The $1 \mathrm{~mm}$. white target was still invisible. The peripheral island of vision in the right eye had also expanded. The left disc was still hyperæmic and its margins were blurred, but the swelling had almost subsided and all hæmorrhages and exudates had disappeared. The sheathing along the superior temporal vessels was now very marked and there was a patch of choroiditis adjacent to the disc margin where these vessels crossed it. The other neurological abnormalities parsisted unchanged. The blood Wassermann reaction was now negative.

The date of primary infection could not be discovered, but it seems clear that it must have been at least 16 years before the present attack of optic neuritis. The multiple cranial nerve involvement suggests that the pathology is one of chronic syphilitic meningitis.

\section{The Clinical Course of Syphilitic Optic Neuritis}

$20 \mathrm{mg}$. par $100 \mathrm{ml}$., Lange curve 0000000000 ).

The patient was given 600,000 units of procaine penicillin daily for three weeks. Visual acuity in the left eye had improved by then to $6 / 24$, the swelling of the disc was subsiding, and a white sheathing of the superior temporal vessels had developed. The macular exudate remained.

He was seen again in January, 1950, having had no further treatment. The acuity was now $6 / 12$ in the left eye. He considered this to be his normal vision, for he had had the keratitis for a long time. The visual fields

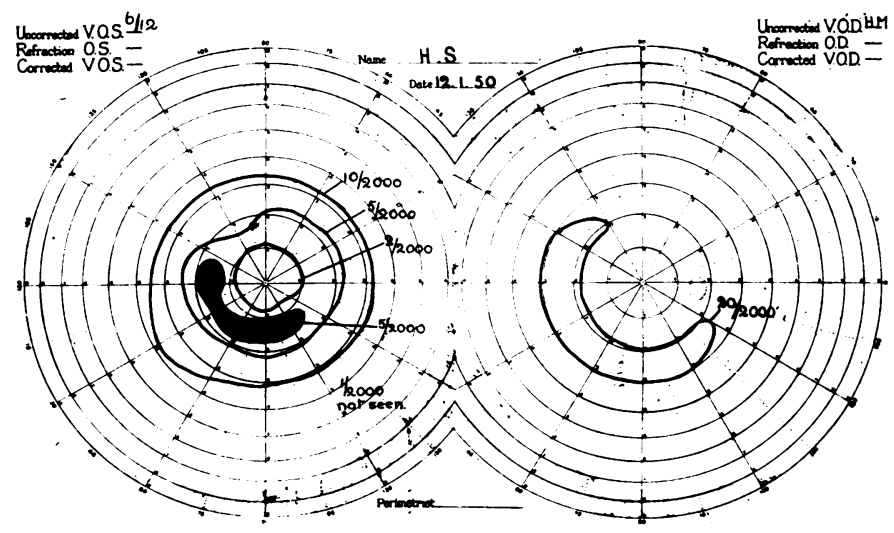

Fig. 10.-Case 5. (January, 1950) V.A. H.M. 6/12. Fields now show $R$. eye : enlargement of peripheral island of vision suggesting an original central scotoma breaking through to the periphery in the upper temporal quadrant. L. eye : reduction in size of blind spot; nerve bundle scotoma in lower quadrant, expansion of isopters. $1 \mathrm{~mm}$. target not seen.
Optic neuritis may occur in syphilis in three forms ; (1) as an exacerbation of congenital infection, (2) in the secondary stage, and (3) as a feature of the tertiary meningo-vascular period. Of the five cases described one falls into the second group and the other four into the third. The ocular disturbance itself, however, does not appear to differ in these various stages.

The onset is usually abrupt, blurring of vision being noticed suddenly, and this may increase in density for a period of days or weeks and then remain stationary, or even sometimes improve a little spontaneously. Headache, or ocular pain, was mentioned by one patient only, a surprising feature in view of its frequency in the common acute retrobulbar neuritis.

Visual Acuity.-The outstanding feature of these cases is the fact that visual defect has only been noticed subjectively in one eye, whereas ophthalmoscopic changes have been present in both. Case 5 is an exception, but his opposite eye has been amblyopic for many years. This seems to be of considerable diagnostic importance, since other forms of bilateral optic and retrobulbar neuritis produce bilateral visual failure. The reduction 
in acuity was to less than $6 / 60$ in two cases and to a level above this in the other three.

Ophthalmoscopic Changes.-In four patients the fundus showed changes typical of papillitis. The disc was intensely hyperæmic, its margins were blurred and the cup filled in, the retina and disc being of a uniform redness. Swelling, however, was minimal, insufficient to submerge the blood vessels, and there were no hæmorrhages or exudates. In Case 5, however, the changes were different. Here there was a gross œdema of the disc head and spread of inflammation, first to the superior temporal vein, producing periphlebitis with hæmorrhages and later fibrous scarring and, secondly, to the choroid producing local choroiditis. In this case there was also an accompanying vitreous haze.

The disc changes have tended to subside more slowly than the improvement in acuity resulting from treatment and have usually been incompletely reversible. Even with restoration of normal vision for long periods, the disc margins have remained indefinite and the physiological cup has not returned, a result presumably of glial overgrowth. Only in Case 5 has post-neuritic atrophy been seen. In Case 1 a patch of choroiditis was present in the macular region, but developed after the onset of the optic neuritis.

Changes in the Fields of Vision.-The earliest changes are to be seen in subjectively unaffected eyes. Here we may note as characteristic findings (1) an enlargement of the blind spot, and (2) a concentric constriction of the smaller isopters both white and coloured. Provided these changes are not marked, they are compatible with normal vision. They indicate a very slight disturbance of the whole cross section of the nerve and an interference with visual reception in the retina immediately surrounding the disc. When more severe, as in Cases 4 and 5, visual failure will occur in the absence of any localized central defect in the field. Damage to particular groups of nerve fibres may then occur, however, and result in corresponding field changes. Thus involvement of the papillomacular bundle will produce central or paracentral scotomata (Cases 1, 2, and 3), whilst damage to other segments will produce nerve bundle defects radiating from the blind spot (Cases 1 and 5). In a further case, only seen once and, therefore, not reported in full because of insufficient data, a complete inferior altitudinal hemianopia together with a central scotoma was seen.

These changes have been more or less completely reversed by treatment, particularly the central scotomata, so that normal acuity has been restored.
Other Neurological Abnormalities.-In three cases $(1,2$, and 3$)$ neurological examination was otherwise normal. In one of these the optic neuritis occurred in the secondary stage, in the other two in the tertiary stage. Case 4 showed evidence of minor cord changes : absent ankle jerks and diminished vibration sense in the feet and ankles. Case 5 showed evidence of multiple cranial nerve damage, the nerves being presumably involved in a chronic basal meningitis.

Serology and Cerebrospinal Fluid Changes.-The blood Wassermann reaction was positive in all cases and the cerebrospinal fluid Wassermann reaction only positive in those cases showing changes in the fluid (Cases 2 and 4). These latter changes consisted of increases in the cell count and protein content and changes in the Lange curve, one paretic, one mildly luetic. It seems justifiable to conclude, in view of the normal findings in some cases, that syphilitic optic neuritis may occur in the absence of diffuse meningeal changes.

Prognosis.-In marked contrast to syphilitic optic atrophy, the prognosis of syphilitic optic neuritis is good with adequate anti-syphilitic treatment. Cases 1,2 , and 3 were treated with penicillin followed by courses of arsenic and bismuth and have regained normal vision. In Cases 1 and 3 the blood Wassermann reaction has become negative, whilst in Case 2 the cerebrospinal fluid became normal and the blood Wassermann reaction only weakly positive after a period of 18 months. Cases 4 and 5 , treated with penicillin alone but in larger doses, have not been followed up so long; in Case 4 normal vision has been achieved but the blood Wassermann reaction remains strongly positive after four months. In Case 5 there has been a very considerable improvement in vision and a reversal of the blood Wassermann reaction after five months. When the condition is neglected, however, serious loss of vision may occur, as exemplified in the earlier history of Case 5, who had an attack of optic neuritis in his right eye 16 years previously, with no recovery and the development of a severe post-neuritic atrophy. The condition was not diagnosed at that time and no treatment was given.

Differential Diagnosis.-The condition has to be distinguished from $(a)$ acute retrobulbar neuritis of non-syphilitic origin, and (b) other syphilitic disorders producing comparable ophthalmoscopic changes.

In the common demyelinating acute retrobulbar neuritis the disturbance is unilateral and the patient usually experiences headache and ocular pain. The disc may be normal or show papillitis and there 
is marked tendency for atrophy to develop even when vision has recovered. Syphilitic optic neuritis, on the other hand, tends to be bilateral from the start, though vision may only be affected in one eye. Spontaneous remission is usual in the first and probably uncommon in the second. Of the field changes the existence of defective acuity in the absence of a central scotoma is a point in favour of a syphilitic ætiology. Differentiation from the much rarer acute bilateral retrobulbar neuritis may be more difficult. In either case, diagnosis must depend on the finding of a positive Wassermann reaction.

Syphilitic optic neuritis has to be distinguished from (1) hyperæmia of the disc occurring in the secondary stage of infection, (2) syphilitic papillœdema as a sequel to hydrocephalus due to a gumma or acute or chronic meningitis and, possibly, (3) syphilitic opto-chiasmal arachnoiditis. Hyperæmia of the disc is rare and is noticed only incidentally, since it produces no visual symptoms. Papillœdema may be difficult to differentiate from the early stages of optic neuritis as it, too, may produce little or no visual impairment. Its underlying cause will usually give rise to distinguishing symptoms and signs, however, and confirmation will be obtained by finding a raised cerebrospinal fluid pressure. Opto-chiasmal arachnoiditis is impossible to diagnose with certainty clinically, but it can cause ophthalmoscopic and field changes similar to those of optic neuritis. It should, perhaps, be considered in cases of apparent neuritis which fail to improve with treatment.

\section{Discussion}

Many names have been attached to this and similar syphilitic disorders of the optic nerve including neuroretinitis, perioptic neuritis, retrobulbar neuritis, papillitis, gumma of the nerve head, opto-chiasmal arachnoiditis, choroiditis juxta papillaris. This confusion of nomenclature is doubtless due, in part at least, to the absence of histological study of the earliest manifestations of the disease. The few pathological findings which have been reported have concerred cases which have progressed to late atrophy of the nerve. They have shown that the nerve fibres are involved secondarily to an inflammatory reaction in the sheaths and septa of the nerve. This reaction has keen most marked in the intracranial portion of the nerve and less extensive in the intraorbital part. Such facts are difficult to reconcile with the clinical picture, for it would appear altogether probable from this that the initial focus of disease is situated in the papilla, and that spread of the disease may occur either into the retina and choroid, or backwards along the nerve itself. In the first case neuroretinitis or choroiditis juxta papillaris may result, in the second perioptic neuritis, or even opto-chiasmal arachnoiditis. Should the process be very intense then actual gumma formation in the papilla might occur. Another rare but interesting syndrome is that described by Fuchs (1926) as neuritis papulosa, a syndrome consisting of enormous swelling of the disc, periphlebitis and choroiditis. In this condition fibrous adhesions may later develop between the papilla and the patches of choroiditis, giving rise to a picture of retinitis proliferans. Case 5 here would seem to fall into this catezory, but it is felt that the initial localization of the disease in this case was essentially similar to that in the other four cases, the difference in the clinical picture being due to the intensity of the papillitis and to a spread of inflammation to involve the retinal veins on the one hand and the choroid on the other.

In the absence of precise pathological details it has, therefore, been felt desirable to describe the condition as one of optic neuritis. The term retrobulbar neuritis has little to commend it, for it seems extremely doubtful whether the classical picture of this condition, namely, a central field defect occurring without alteration of the optic nerve head ever occurs in syphilis. When central scotomata occur with primary syphilitic optic atrophy, the underlying pathology is one of meningeal involvement. Papillitis may possibly prove to be a more exact description, but it suggests a restriction of the disease process which is, as yet, unsupported by pathological findings.

The literature on the subject is scanty. Apart from a few reports of single cases, the only considerable contributions have been those of Wilbrand and Saenger (1913), Igersheimer (1918) and, more recently, Walsh (1947). Wilbrand and Saenger's three cases each had unilateral post-neuritic atrophy with central scotoma or concentric constriction of the visual field. Two were examined post-mortem and showed fibrous thickening and cellular infiltration of the sheath and septa of the nerves with atrophy of the margin nerve fibres. They considered that the initial lesion was in the papilla with subsequent spread backwards to the optic nerve, and that the optic neuritis was not part of a more widespread syphilitic meningitis. Igersheimer (1918) gives brief details of 13 cases of optic neuritis. All but two recovered normal vision after treatment, and in most cases the fundus also returned to normal. Igersheimer also thought that the inflammatory disturbance was focused at the papilla. He stated that it occurred more commonly in the absence of other neurological abnormalities, some- 
times in the secondary stage of infection, but more often later. He explained the field changes as due to nerve bundle defects, central scotomata being the result of involvement of the papillo-macular bundle as it lies superficially in and behind the papilla.

Walsh (1947) attempts to distinguish between perioptic neuritis, neuroretinitis, retrobulbar neuritis and gumma of the nerve head. The result is not very satisfactory, as the clinical features of these several conditions overlap. He describes four cases ; one clearly had a chiasmal lesion, another possibly had tobacco amblyopia. The other two were not examined in the early stages and atrophy of the nerve had developed associated with central field defects. Two improved with anti-syphilitic treatment and two did not.

Sloan and Woods (1938), in a study of visual field defects in syphilis, record the changes in three cases of active optic neuritis, one occurring in the secondary stage, two due to neurorecurrence. All showed enlargement of the blind spot and either nerve bundle lesions or central scotomata.

Mention must also be made of syphilitic optochiasmal arachnoiditis, a condition dealt with in particular by Bollack, David, and Puech (1937) and Hausman (1937, 1941, and 1942). Such a diagnosis can only be established by surgical exploration, and although this has mainly been done in cases of optic atrophy unresponsive to treatment, yet some patients have presented with papillœdema. The combination of this with diminished visual acuity and field defects raises the question of its differential diagnosis from syphilitic optic neuritis as here described. Clinically, this would seem at times to be impossible until the effects of anti-syphilitic treatment have been observed, for whereas optic neuritis responds well to therapy, arachnoiditis is seemingly refractory.

\section{Summary}

Five cases of syphilitic optic neuritis are described. The condition is one which may occur in the secondary or tertiary stages of infection. Its mode of presentation is similar to the commoner demyelinating acute retrobulbar neuritis, in that unilateral failure of vision is complained of but, characteristically, bilateral ocular changes are found. The clinical features are described and the favourable results of treatment contrasted with the lack of response in syphilitic optic atrophy.

I wish to thank Dr. F. R. Ferguson and Dr. G. E. Smyth for permission to record the details of patients under their care.

\section{REFERENCES}

Bollack, J., David, M., and Puech, P. (1937). "Les Arachnoildites opto-chiasmatiques." Paris.

Fuchs, A. (1926). Z. Augenheilk., 58, 315; 59, 213. To iv Hausman, L. (1937). Arch. Neurol. Psychiat., Chicago, $\frac{\vec{D}}{\vec{D}} \vec{\sigma}$ 37, 929 .

(1941). Amer. J. Ophthal. 24, 119. (1942). J. Mt. Sinai Hosp., 9, 544.

Igersheimer, J. (1918). "Syphilis und Auge." Berlin.? Sloan, L. L., and Woods, A. C. (1938). Arch. Ophthal., Chicago, 20, 201.

Walsh, F. B. (1947). “ Clinical Neuro-ophthalmology."

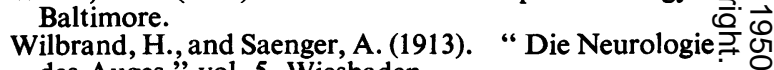
des Auges," vol. 5. Wiesbaden. 